\title{
Accident, or Homicide? Sub-Register of Infant Death Cases, Undetected Neglect and Abuse
}

\author{
María Teresa Sotelo* \\ President of Fundación en Pantalla Contra la Violencia Infantil, Mexico
}

Submission: February 12, 2018; Published: February 19, 2018

*Corresponding author: María Teresa Sotelo, Researcher, President of Fundación en Pantalla Contra la Violencia Infantil, Mexico, Tel: +5215529197883; Email: teresotelo@hotmail.com

\begin{abstract}
The average rate of infanthomicides (recognized) In underdeveloped countries is of $6.6 \%$. In developed countries $2.3 \%$ per 100,000 inhabitants. Although this rate comes from a worthy statistic sources, is farther from reality, due that Innumerable murders of children, not properly identified, vanished into anonymity. The American Academy of Pediatrics adverted that in $63 \%$ of the cases, declared as Sudden Infant Death Syndrome, in reality were accidents, in most cases, intentional suffocation homicides, perpetrated by parents or by caregivers. Lamentably, it is a common practice in health institutions, not to scrutinize the death by infectious diseases in children from 0 to 9 years old, with post mortem analysis. It is a prevailing custom on neglect mothers to feed the baby with unwashed milk bottles, infected with larvae. Very so often, clinical reports of severe malnutrition, frequently correlates children deprived of nourishment, as a cruel practice of their parents. Deaths clinically reported as infectious, many hides intentional poisonings.
\end{abstract}

Keywords: Child abuse; Infections; Detection; Subregister post mortem

\section{Introduction}

There is a subtle difference, but of deadly consequences, not adequately feeding a child for economic reasons, from not feeding him/her because of inflicting punishment. It is uneven not obtaining potable water to wash a baby bottle, from not to wash it out, because of indolence. There is a big difference not protect the child from the cold, due to lack of money, that stripping him/her the clothes, to rejoice with the suffering of the child.

In this divergence of concepts, errors lie in the medical diagnosis regarding diseases and deaths caused by child abuse. Countless deaths classified as pneumonia, anemia and intestinal infections were induced by maltreatment, negligence and of The Syndrome of Munchausen. The $10 \%$ of the population attends at a pediatric hospital, corresponds to abuse and neglect cases Loredo A [1].

This asseveration may surprise some, due that cases of child abuse most of the times, are linked just to scandalous physical trauma, burns, or injuries. Nevertheless, child abuse occurs silently in cases of parental negligence, and the Syndrome of Munchausen. The Mexican Ministry of Health, Carried out a survey in 2008, to determine the rank of deaths preventable diseases in children. The $11 \%$ corresponded to children less than one year, $38.1 \%$ in ages between the year and four years, and $32.8 \%$ for children between 5 and 14 years.

Despite the lack of information to which I alluded, and the consistent sub classification of deaths, due to parental negligence in childhood, the statistics offers a guidelines emblance of the problem. The International Organization, Save of Children, states in its publication "Los Peligros para la Niñéz in Mexico that $12.4 \%$ of children from 0 to 59 months of the country, suffer from malnutrition. The mortality rate of children under 5 years old (deaths per thousand live births) is $13.2 \%$. The document indicates that the homicide rate for girls and boys is 5.5\% per 100000 inhabitants, whose ages range from 19 to 19 years in the year 2015 .

In underdeveloped countries with enormous economic limitations, to support substantial budgets to health institutions are denied, restricting the hospital's guidelines to select the endemic issue relevant to deal with. Generally the child abuse and neglect, is not considered among the public health issues, even when this is considered by the WHO, as a global public health scourge, furthermore, is the first child's morbidity in underdeveloped countries, being Afganistán the country with the highest infant mortality rate in the world, more than 120 out of every 1,000 births die. México and Haiti is to occupies the first place in parental homicides. Source: OECD (Figure $1 \& 2$ ). 


\section{Muertes en infantes prevenibles}

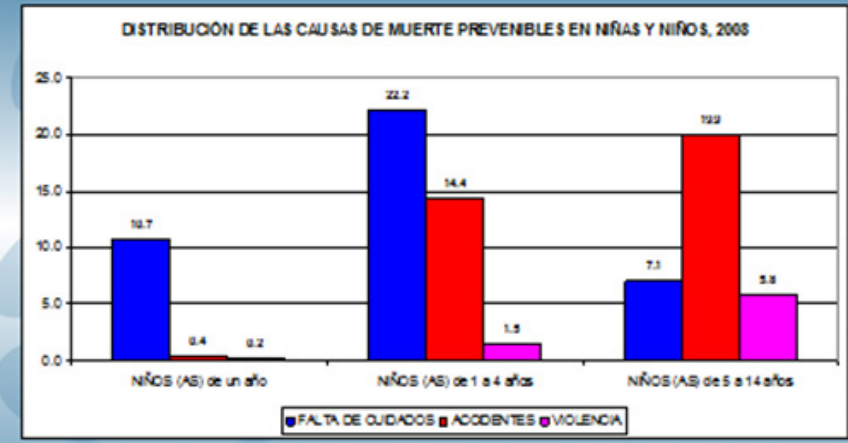

Nota: Falta de cuidados: Se incluyen desnutición, enfermedades infecciosas. anemia. Violencia: Se incluye homicidios y suicidios. Fuente: SSA.

De acuerdo a las causas de muerte de los niños reportadas por la SSA, mueren por causas prevenibles, el $11 \%$ de los menores de un año, el $38.1 \%$ de los comprendidos entre el año y los cuatro años y el $32.8 \%$ de los niños (as) de entre 5 y 14 años.

Figure 1: Distribution of preventable causes of death in girls and boys 2008. Lack of care (blue) accidents (red) violence (purple). This classification included homicides and suicides. Malnutrition, infectious diseases, anemia were included. Source: Secretary of health. Mexico.

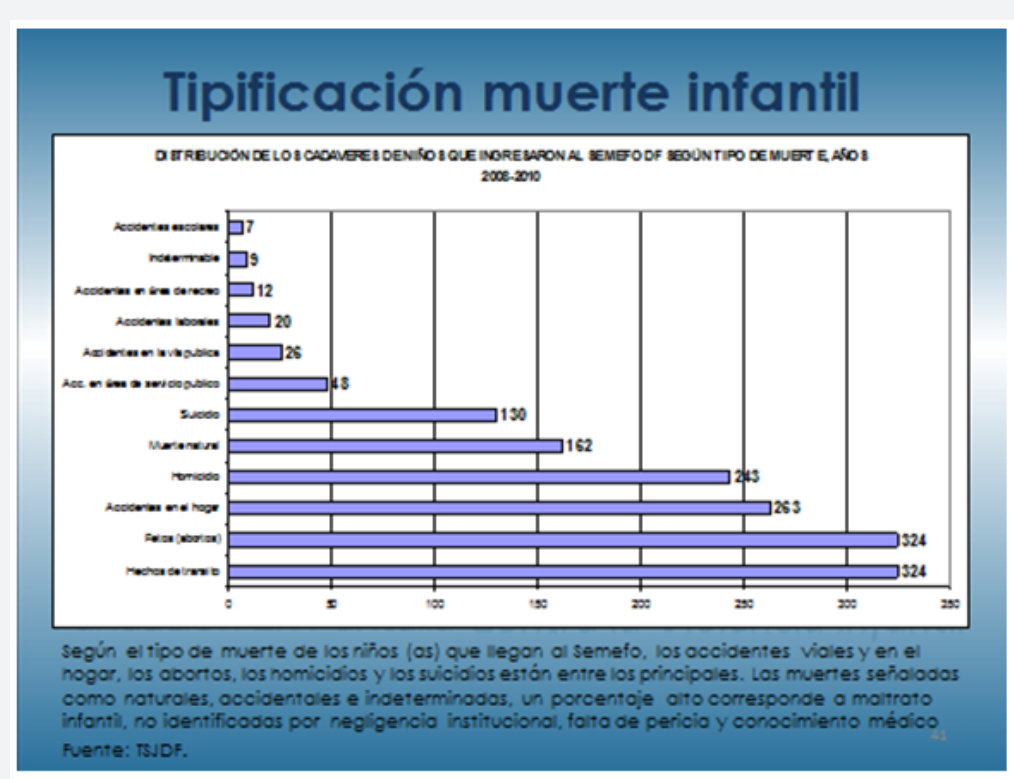

Figure 2: Abortions, homicides and suicides are among the main ranks, notwithstanding the declaration deaths indicated as natural, accidental and indeterminate. (The high percentage of deaths, corresponded to child abuse, not identified).

\section{Presentation of the Case}

\section{Typification of infant death underlying child abuse}

A 5-year-old girl, victim of physical abuse and neglect. The mother was the suspected aggressor. The mother reported that the 5 year old girl, while playing, the television that rested on the furniture, had fallen on her daughter's head; likewise there had been a short circuit which had caused her hand to get burned.

She arrived at the hospital in serious conditions, with cranioencephalic fracture, her hand totally burned. It had to be amputated. The narrative of the mother, from beginning to end, was plagued with contradictions. The severity of the injuries with the sequential argument did not match. The degree of the malnutrition, indicates that she was a victim of multiple abuse. According to the nurse's account, the mother during hospital visiting, was cold and displeased with her daughter, there was no physical contact or any sign of affection.

According to the contention of the medical staff, the complaint of child abuse had been submitted in time to the public prosecutor's office, who rejected the clinical diagnosis 
of presumptive child abuse, instructing the hospital to give the patient back to the mother, once she were in healthy conditions.

Fifteen days after, the girl was released from hospital confinement in good conditions, was again admitted through hospital emergencies under severe conditions of malnutrition. Finally the victim died, without having done justice to child, leaving the mother without any legal imputation for the crime. This case leaves many questions unanswered. Did the hospital proceed to the legal complaint timely? Faced with such an obvious situation of physical abuse, will the public prosecutor have determined to risk the girl? Returning her the mother? Unfortunately the death occurred, and it is not feasible to know the truth behind (Figure 3).

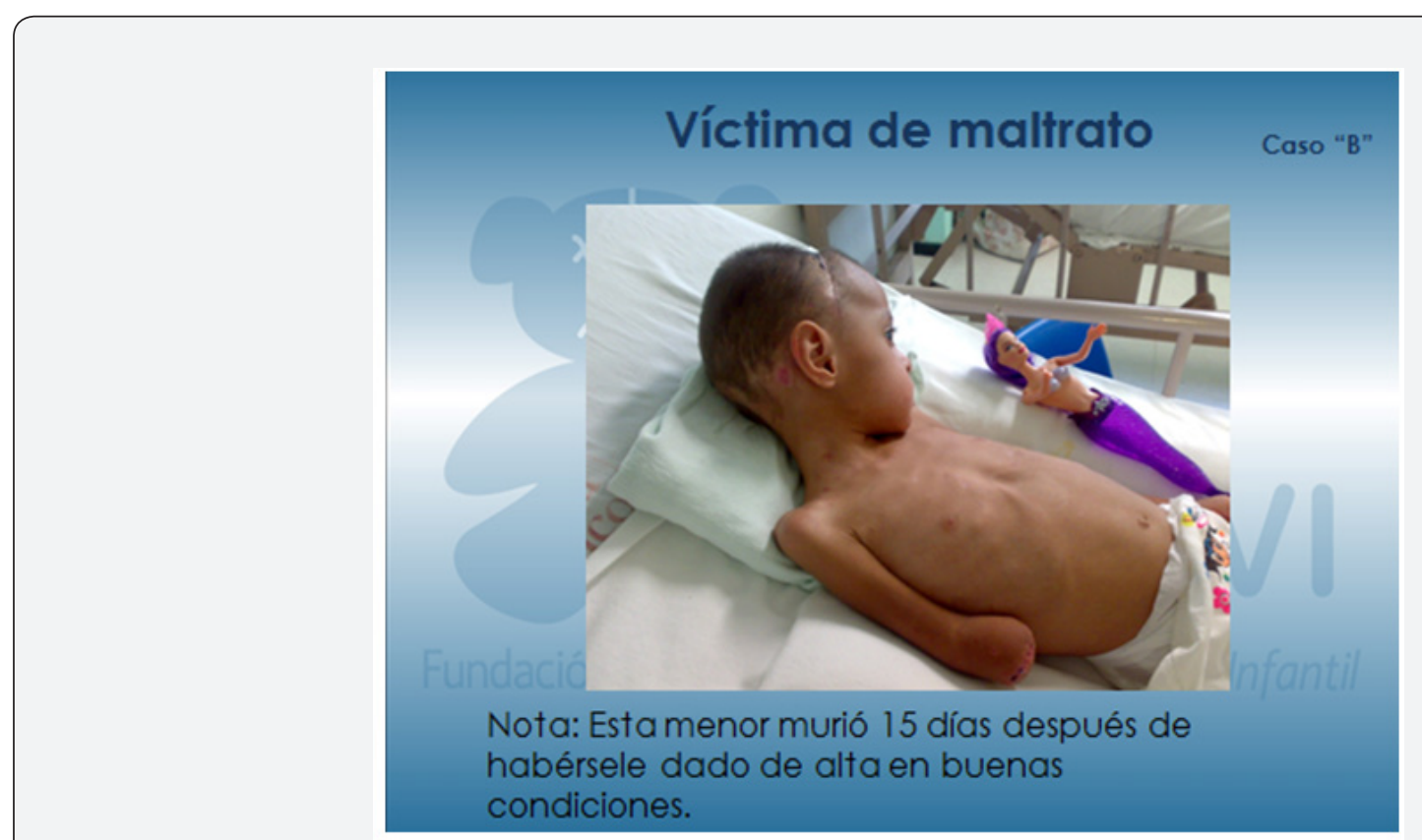

Figure 3:

\section{Discussion}

The referred case report says the dimension of covert mistreatment in medical institutions, whether by medical neglect, lack of knowledge of regulating institutional procedures, or default training about Kempe Syndrome.

While it is difficult for the pediatrician, to determine the underlying causes of the illness, it is recommendable at the slightest doubt of abuse or neglect, to order laboratory and cabinet studies, incorporating a checkup methodical standards of size, weight, vaccines, dental condition, as well general cleanliness. It is advisable to consider the parents behavior during child hospitalization, assessing sequential part of events. Is the child regularly visited during hospital staying? Or, there is a recurrent abandonment. Visual and corporal contact familychild, describe the emotions of both, particularly when it comes to a victim-victimizer relationship. There are five elements in variably present in abusive families; the narrative incident falsehood, manipulation of the facts, complicity, cruelty, and the silent witness.

It is advisable to gather information on the clinical history, the answers could yield valuable details regarding the child's clinical ambulatory background. Has the child been hospitalized frequently? Why? It is recommendable to inquire, which hospitals, and who attended the boy/ girl. When obtaining these clue data, the chronological information background should be cross; Hospital movements, dates and causes. Victimizing parents, invariably change the health service, with a medical institution ambulatory story behind, so as not to arouse suspicion among health personnel. Deceased children, as well as frequent abortions, is a remarkable characteristic of abusing parents, this antecedent is a valuable red focus, to take into account as a predictability of Munchausen, in killer mothers. Though, before issuing a diagnosis of child abuse, all clinical, social and psychological antecedents, must be gathered, thereafter all the pieces are accommodated, and the dark elements begin to narrate a possible outcome. A thorough analysis must be done, to avoid falsehood of legal complaint of abuse, when it was not.

In my professional experience, the pediatric hospitals, that integrates a interdisciplinary team for the detection and comprehensive care of child abuse, with trained personnel: Pediatrician, social worker, paido psychiatrist, and the lawyer (to assume legal issues) the result is surprisingly efficient to detect cases, due that the medical and paramedical staff, feel released from direct responsibility of presenting the legal procedures, and to get involved in the tricky lies of violent families. 
Considering the complexity of the Syndrome of Kempe, having a team of specialists; medical and paramedical staff, are not distressed in inquiries, of legal issues, whereas, these are carried out by the lawyer of the interdisciplinary child abuse specialized team. It usually works as follows: When a pediatrician during a routine consultation, suspects of a possible case of child violence, he refers the case to the assigned team of experts, who through an exhaustive clinical, social and circumstantial evaluating facts, they altogether arrives with an accurate diagnosis, that confirms or discards the pediatrician suspicion.

\section{Conclusion}

Even though the undeniable advances in the field of medicine, the protection of children from abuse, continues to be weak in stagnant terrain in many countries. After many years, dealing with medical practitioners and principals, the experience has shown me, that when a pediatrician with not high standards of ethics, is faced with a child abuse potential case, which procedures involves innumerable procedures, other assumption of taking risky legal steps to confront the abuser, many fix on, to cover up an abuse, even when the legal complaint is mandatory.

Nevertheless a hospital designed lawyer working with an interdisciplinary team of experts, is by far, the most effective institutional scheme, to prevent and detect child abuse. It is imminent to adequate clinical protocols that include scrutiny in diagnosis laceration of internal organs, respiratory and

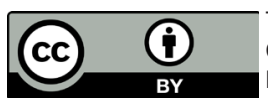

This work is licensed under Creative Commons Attribution 4.0 Licens DOI: 10.19080/JOJCS.2018.06.555682 intestinal infections, or recurrent diseases in the kid to inquire potential Syndrome of Munchausen or neglect.

It is not a matter of disregard the lack of protocols and medical mistakes, in the diagnosis of child abuse, the outcome has invariably been of fatal consequences for the little victim. No matter the weight of the law was evaded, to be the indirect responsible, or, co-responsible of the infant death, it will always be a crime, which in one way or another culpable must assume.

\section{References}

1. Loredo AA (2004) Maltrato en niños y adolescentes. Editores de Textos Mexicanos, México.

2. Tomé P, Reyes H, Piña C, Rodríguez L, Gutiérrez G (1997) Características asociadas al subregistro de muerte en niños del estado de Guerrero, México. Salud Pública Mex 39(6): 523-529.

3. Child abuse (2002) National Library of Medicine. Medline Plus, En línea, Fecha de consulta 5 junio 2002.

4. Dubowitz H, Giardino A, Gustavson E (2000) Child neglect: guidance for pediatricians. Pediatr Rev 21(4): 111-116.

5. de Terreros IG (1995) Los profesionales de la salud ante el maltrato infantil. Granada: Editorial Comares.

6. (1998) Medical necessity for the hospitalization of the abused and neglected child. American Academy of Pediatrics. Committee on Hospital Care and Committee on Child Abuse and Neglect 101(4 Pt 1): 715-716.

7. Fundación en Pantalla Contra la Violencia Infantil.

8. Save the Children. - los peligros para la niñez. Indicadores Para Mexico. 